\title{
Mis encuentros con José Luis Aranguren
}

\author{
ERNESTO GARZÓN VALDÉS
}

En diciembre de 1950 llegué a Madrid becado por el entonces llamado Instituto de Cultura Hispánica. Dos fueron las razones principales que motivaron mi decisión de estudiar en España. La primera tenía una connotación negativa: estaba francamente cansado de lo que percibía como una penetrante mediocridad universitaria impuesta en aquellos años por profesores cuyo único mérito era su filiación peronista y a quienes parecían no molestarles las leyendas en las paredes de los edificios cercanos a la Universidad con textos tales como «Haga patria, mate un estudiante» o «Libros no, alpargatas sí». La imposición de la corbata negra a todo empleado público a raíz de la muerte de Eva Perón, la letanía radial cotidiana de su paso a la inmortalidad a las 8,25 de la noche, el uso de la motoneta como medio de transporte presidencial, la presencia de Perón en congresos de filosofía exponiendo su pensamiento filosófico arropado con un heterogéneo catálogo de citas de Parménides, Sócrates, Hesíodo, Protágoras, Jesucristo, Tomás de Aquino, Spinoza, Leibniz, Hobbes, Voltaire, Hegel, Marx, entre otros, y ataques al racionalismo filosófico y al liberalismo político ${ }^{1}$, la peronización de la Suprema Corte de Justicia, el dudoso carácter de la Fundación Eva Duarte de Perón que, no obstante ser privada, recibía una vez al año en calidad de donación el total de los ingresos nacionales de un día, eran elementos de una realidad político-social que habían transformado a mi país en un hábitat insoportable.

La segunda motivación tenía una connotación positiva: aunque de forma indirecta y algo imprecisa, sabía que en Madrid existía un grupo de intelectuales que, no obstante las características del régimen político imperante (que en muchos aspectos no se diferenciaba del argentino), mantenían una posición de larvada oposición liberal y, además, eran excelentes profesores cuando no filósofos de primera categoría como Xavier Zubiri. Por otra parte, España significaba, desde la óptica de un argentino provinciano, Europa.

Tuve la suerte de aterrizar en el Colegio Mayor de Nuestra Señora de Guadalupe, en la calle Donoso Cortés 65, dirigido por Antonio Lago Carballo. Antonio era (y sigue siéndolo) una mezcla perfecta de hábil administrador y de intelectual abierto y desprejuiciado, con una inquebrantable fe en las posibilidades de cooperación universitaria en el ámbito hispánico. Estas dotes son las que explican la selección de los escolares tanto españoles como hispanoamericanos del Guadalupe. Entre los primeros, algunos nombres pueden

' Cfr. el discurso de Juan Domingo Perón en el acto de clausura del Primer Congreso Nacional de Filosofía en Mendoza, el 9 de abril de 1949. 
ilustrar la calidad intelectual de esa residencia: Juan y José Agustín Goytisolo, José Ángel Valente, Emilio Lledó y Aurelio Menéndez Menéndez ${ }^{2}$; entre los hispanoamericanos: Ernesto Cardenal, Julio Ramón Ribeyro, Hernando Valencia, Ernesto Mejía, Alfonso Carro, Guillermo Bedregal, Alberto del Campo y Juan Carlos Agulla.

Pero Antonio Lago no sólo sabía seleccionar colegiales, sino que también procuraba que el Guadalupe fuera un centro de encuentro con intelectuales españoles de otras generaciones mayores que la mía. $\mathrm{Y}$ así, era frecuente que profesores de la talla de Enrique Gómez Arboleya, Julián Marías, Pedro Lain Entralgo, Joaquín Ruiz Giménez, Manuel García Pelayo, José Javier Conde, Luis Díez del Corral o Antonio Tovar compartieran la sobria mesa de la comida o la cena con los colegiales. Ser invitado a esos frugales ágapes de menú harto precario era considerado por los hispanoamericanos como un alto honor y una vivencia inolvidable. Era, a la vez, un desafio: nada cuesta más esfuerzo que mantener un diálogo medianamente inteligente con personas que uno considera superiores en talento e información. Y así conocí un día a un hombre huesudo, con un rostro como recortado a hachazos, gruesas gafas, no muy locuaz pero de inteligencia aguda y diálogo nunca exento de un humor que no dejaba de contrastar con su aspecto severo: José Luis Aranguren.

Para alguien que como yo había tenido una formación católica estricta, consolidada a través de muchos rosarios familiares, de meses de María, de comunión de los primeros viernes, de promesas a la Virgen y a Santo Domingo para aprobar exámenes o conseguir los favores de algún amor en esos años imposibles, todo ello con un dejo de beatería e intransigencia, el encuentro con alguien que se tomaba el catolicismo en serio pero, al mismo tiempo, se adentraba en la problemática del protestantismo y trataba de entenderlo desde adentro significó una especie de shock que, con el tiempo, habría de contribuir a cambiar mi concepción religiosa del mundo.

En aquellas reuniones del Guadalupe, Aranguren nos hizo conocer buena parte de los argumentos que en 1952 fueran incluidos en su libro Catolicismo y protestantismo como formas de existencia. Recuerdo que el enfoque de Aranguren y su conocimiento de una filosofía que en aquellos años me fascinaba -el existencialismo - me impulsaron de alguna manera a despojarme de una visión maniquea y crearon en mí la saludable inseguridad de la duda.

Esto por lo que al tema religioso se refiere. Pero había algo más. Desde la Córdoba argentina, la existencia de dos Españas irreconciliables parecía un problema obvio de solución imposible. No dejó de sorprenderme en aquellos años de Madrid el espíritu de tolerancia de Aranguren puesto de manifiesto

${ }^{2}$ José Manuel Caballero Bonald se ha referido a cste ambiente cultural del Guadalupe desde su punto de vista de poeta: «En cierto modo también, el Guadalupe fue uno de los más peculiares ámbitos de gestación de los escritores de mi edad que integrarian luego -incluso por razones vagamente amistosas- el grupo generacional del 50.n (Cfr. José Manuel Caballero Bonald, Tiempos de guerras perdidas, Barcelona, Anagrama, 1995, p. 318.) 
en un trabajo publicado en Cuademos Hispanoamericanos en 1953. Los escolares del Guadalupe teníamos un estrecho contacto con esta revista editada por Cultura Hispánica y en la que muchos de los hispanoamericanos publicamos nuestros primeros artículos (deficicntes en su mayoría, signados por una cierta petulancia con la que tratábamos de disimular la falta de originalidad y/o conocimiento). Los númoros de Cuadernos eran, por ello, leídos y comentados por todos nosotros. Justamente allí publicó Aranguren «La evolución espiritual de los intelectuales españoles en la emigración». Creo que entonces, por primera vez, tuve una idea más o menos cabal de la tragedia cultural de la guerra civil. He vuelto a releer párrafos de este artículo recogidos por Elías Díaz en su imprescindible libro Pensamiento español, 1939-1975. Y ahora, con la distancia de cuatro décadas y tras la experiencia personal del exilio, comprendo mucho más las razones de Aranguren y no deja de complacerme el hecho de que ya entonces me impresionara su invitación a procurar entender los argumentos del otro a través del diálogo. Tal vez convenga reproducir algunas de sus ideas:

« No es absurdo que entre ellos y nosotros esté cortada casi toda comunicación pública? En lo que a nosotros concierne, des hoy tan rica nuestra vida intelectual como para que, sin gravísimo menoscabo, pueda prescindirse de la aportación de los emigrados? [...] ¿No habrá que calificar, por lo menos, de anómala esta incomunicación en que persistimos con nuestros compatriotas emigrados? [...] iNo ha llegado la hora de que, al margen de las diferencias políticas, aceptándolas, pero sólo en lo que estrictamente son, diferencias políticas, nunca barreras para la inteligencia, dialoguemos los unos con los otros? ${ }^{3}$.

Ésta fue, posiblemente, la segunda enseñanza que recibí en aquel tiempo de Aranguren: la necesidad de mantener abierto el canal de comunicación tolerante como actitud auténticamente intelectual: la necesidad de «regresar siempre al diálogo", como le gustaba decir.

En julio de 1953 dejé Madrid para iniciar mi primera estancia alemana. Pienso que ya entonces habia dejado de ser el universitario provinciano, religiosamente beato y políticamente intransigente. Como suele suceder cuando se tienen veintitantos años, alentaba también no pocos sentimientos de frustración y fracaso: una actitud de arrogancia intelectual me impidió entregar la tesis doctoral que había escrito por considerarla desprovista de toda originalidad. Hoy creo que hice bien; en aquellos años lo consideré un desastre. Pero no todo era negativo: de mi contacto con profesores españoles intelectualmente honestos y políticamente tolerantes, como José Luis Aranguren, había experimentado el atractivo irresistible de una aventura intelectual que estaba dispuesto a vivir sin aceptar las restricciones de la dictadura y la intolerancia.

${ }^{3}$ Cfr. Elías Díaz, Pensamiento español, 1939-1975, Madrid, Cuademos para el Diálogo, 1978, pp. 106 y ss. 
Muchos años después (nada menos que cuarenta), el nombre de José Luis Aranguren apareció nuevamente vinculado a mi vida intelectual: el Instituto de Filosofía me confirió el honor, en marzo de 1993, de hacerme cargo de las Segundas Conferencias Aranguren de Filosofia. Y así, en la Residencia de Estudiantes, sentado en primera fila, volví a ver al profesor que contribuyó a estimular en mí la tolerancia política y religiosa. Su aspecto físico no había cambiado mayormente. Seguía siendo tan enjuto como siempre, su prematura calvicie lo había librado de las alteraciones que implica la pérdida progresiva del adorno capilar y tras sus gafas seguían brillando sus ojos atentamente inquietos. En realidad hay dos formas de conservar el aspecto físico durante décadas: mantener la juventud exterior como una especie de Dorian Gray o envejecer joven y seguir así hasta el final. La primera posibilidad no deja de ser atractiva pero requiere, como diría Javier Muguerza, un «compromiso fáustico» no fácil de cumplir. La segunda, tras ciertos inconvenientes inicialcs, tiene la ventaja de una cierta inmutabilidad que permite estar desde el comienzo all donde había que llegar. Esta segunda posibilidad fue la que los hados brindaron a Aranguren. Pero, dejando de lado las exterioridades, lo más importante fue para mí el percibir que conservaba su espíritu alerta y su clara inteligencia que se manifestaba en sus gestos de asentimiento o discrepancia con respecto al contenido de mis conferencias. Pienso que en lo fundamental coincidimos: yo había insistido en la necesidad de salvar la democracia representativa a través de las limitaciones impuestas por un «coto vedado» a la negociación parlamentaria, Aranguren se había referido en 1979 a los peligros de un «parlamentarismo a ultranza» ${ }^{4}$. Hablábamos, pues, del mismo problema y nuestras soluciones no dejaban de ser similares. Así lo comentamos en aquella ocasión: don José Luis con ese tono a la vez tímido pero firme tan propio de él y yo con la manifiesta satisfacción de coincidir con uno de mis maestros de los años cincuenta.

Ésa fue la última vez que lo vi. Su muerte me dolió como duele la pérdida de aquellas personas que en un momento dado de nuestras vidas, a veces sin proponérselo, imprimen algún cambio de perspectiva que luego resulta ser enormemente fecundo.

Cfr. José Luis Aranguren, La democracia establecida. Una crítica intelectual, Madrid, Taunus, 1979 , p. 68 . 